\title{
¿QUÉ HAY DE LOS FAMOSOS DESTRONAMIENTOS DEL SER HUMANO?
}

\author{
HAS THE HUMAN BEING BEEN REALLY DETHRONED?
}

\author{
Teresa Bejarano ${ }^{2}$ \\ Universidad de Sevilla (España)
}

Recibido: 22-01-2014

Aceptado: 05-03-2014

\begin{abstract}
Resumen: La idea de que el ser humano es la meta de la Naturaleza está claramente fuera de lo comprobable o refutable. Pero podemos preguntarnos si esa idea 'encaja' con los descubrimientos científicos, y, más concretamente, con la evolución pluridireccional y ramificada que ha suplantado a la vieja scala naturae y que parece prohibir nociones meramente descriptivas como las de cúspide o escalones de la evolución. Ciertamente el invocar la indiscutible mayor inteligencia de la especie humana con vistas a colocar a los humanos en la cúspide sería absolutamente inútil a menos que se encuentre una justificación para privilegiar como criterio el de la inteligencia. Pero nosotros podemos enfocar la siguiente cuestión: El avance en la captación de la realidad externa, ¿podría ser realmente una tendencia general de toda la evolución, o, mejor dicho, la más general entre las muchas y variopintas tendencias de avance y especialización que se pueden detectar en la evolución de los seres vivos? Este trabajo sugiere una respuesta afirmativa. Si ésta es correcta, entonces aquel 'encaje' sería ahora mejor, más concreto y menos superficial que antes de que la evolución fuera descubierta.
\end{abstract}

Palabras-clave: conciencia animal, evolución, homología entre cuerpo propio y cuerpo ajeno, percepción (de objeto distal), primates, tropismo, unicidad humana básica; visibilidad de las propias manos.

Abstract: The idea that the human being is Nature's goal is certainly beyond what is verifiable. But we may ask ourselves whether it fits or not with

[1] Quiero manifestar aquí mi agradecimiento a los revisores anónimos. Sus comentarios me han sido sumamente útiles.

[2] (tebefer@us.es) Profesora Titular de Filosofía del Lenguaje en la Universidad de Sevilla desde 1990. La lista de mis publicaciones desde 1979 a 2015 puede consultarse en mi web (us.es.personal/ tebefer), donde pueden descargarse algunas de ellas. 
scientific discoveries. Such 'fit', I propose, is now better and more concrete than before evolution was discovered. Certainly, invoking the indisputable greater intelligence of humans is of no use unless a justification to favour intelligence as a criterion is found. But we can focus on the following question: Is the advance in grasping the reality a general trend in evolution? I suggest an affirmative answer. More concretely, this paper distinguishes four qualitative advances in that ability. In this sense, the difference between tropism and animal consciousness, and even more so, the superiority of primates in comparison with the rest of mammals, are key for that 'fit'.

Key-words: animal consciousness, evolution; matching between one's own body and another's body, perception (of distal objects), primates, tropism, basic human uniqueness, visual perception of one's own hands.

\section{Introducción}

La idea de que el ser humano es la meta de la Naturaleza está por definición fuera de lo comprobable: No hay nada que fuerce u obligue a interpretar teleológicamente los procesos naturales. Así pues, acerca de esta interpretación, sólo cabe hablar de si encaja o no con los descubrimientos científicos. Yo voy aquí a proponer que ese 'encaje' puede ser ahora más detallado y completo que antes de que se descubriera la evolución.

En el prólogo que viene a ser la Sección 1, enfoco los supuestos destronamientos del ser humano que se habrían ido sucediendo desde el comienzo de la ciencia moderna, y entre ellos escojo el vinculado a Darwin como el único punto de interés.

En la Sección 2, empiezo a enfocar la cuestión del 'buen encaje’. El punto de partida para tal encaje habría de consistir en que los humanos pudieran ser considerados el paso más avanzado de la evolución. Pero ¿cómo obtener ese punto de partida? Una vez que nos situamos en el seno del conjunto de los vertebrados de sangre caliente, es difícil atribuir rótulo alguno de 'última adquisición' o 'punto más avanzado' a la especie humana. La antigua scala naturae, unilineal y progresiva, hace ya mucho que fue dinamitada por los hechos. Ahora sabemos que las ramas y las especializaciones detectables en los seres vivos van en muchísimas direcciones, y que aquellas nociones ('la cúspide', 'el punto más avanzado de todos') resultan cada vez más difíciles de aplicar. De hecho cada vez más a menudo el rechazo de esas nociones es asumido como obvio. Nótese que el invocar la indiscutible mayor inteligencia de la especie humana no resolverá la dificultad a menos que se encuentre una justificación para privilegiar como criterio el de la inteligencia. La cuestión, pues, que hay que preguntarse es si la tendencia más general de la evolución podría ser la del avance en la captación de la realidad. 
La sección 3 constituye un paréntesis. Es decir, antes de empezar a responder a la pregunta con la que acababa la sección anterior, inserto una crítica del dualismo actual. A mi juicio, ahora, tras los meandros de siglo y medio de discusión, numerosos defensores del Dios creador están propugnando un modo de aceptar la evolución-como un proceso ineficiente y chapucero en vez de grandioso-que debería serles ajeno, precisamente a ellos más que a nadie.

En la Secciones 4-6 sugiero que a lo largo de la evolución biológica habría habido cuatro avances cualitativos de la capacidad de captar la realidad. El primero es el de los tropismos de vegetales, animales unicelulares o incluso insectos. El segundo, el de la percepción de objetos como distantes del organismo, marca la aparición de la conciencia (cuya función originaria habría sido la de ser centro de la distancia). El tercero corresponde a los primates y a su mano autovisible. Desde la homología entre mano propia y mano ajena, los primates, o, concretando más, el chimpancé, habría llegado a captar la homología entre cuerpo ajeno y cuerpo propio y a tener la expectación (o sea, el perfil predictivo pero vacío) de los estados mentales que él, él mismo, experimentaría si él estuviera en la ubicación, postura y orientación en que se halla un congénere. Por último, estaría la capacidad exclusivamente humana de captar, no ya ese tipo de expectaciones, que en el fondo siempre pertenecerán al rango de los posibles estados del sujeto, sino verdaderos contenidos mentales que sean diferentes a los propios, captación que coincidiría-hay serios indicios de ello-con la exclusividad humana más básica y primitiva.

En la Sección 7, vuelvo al punto inicial. El cuadro esbozado sugiere que a lo largo de la entera evolución ha operado una tendencia de acuerdo con la cual el ser humano estaría en el punto culminante. Esa culminación se puede mostrar sólo en un nivel descriptivo, no teleológico, claro está. Sin embargo, el 'encaje' que se buscaba sería ahora mejor, más concreto y profundo que en la pre-evolucionista scala naturae.

\section{Los famosos destronamientos del ser humano.}

Una de las frases más citadas es la que asocia a Copérnico, Freud y Darwin con sendos destronamientos del ser humano. ${ }^{3}$ Según la tan traída y llevada frase, lo primero en caer bajo el hachazo de la ciencia habría sido la centralidad de la Tierra. Más tarde, la racionalidad humana se habría visto afectada y condicionada por la entera gama de lo inconsciente. Por último (aunque en realidad Darwin es anterior a Freud), la especificidad humana se habría convertido en un punto más en las trayectorias de la evolución. Todo esto forma parte del arsenal de conocimientos casi obligado en nuestra socie-

[3] Ésta, con sólo tres partes, es la formulación básica. Pero hay otras más extendidas: véase, por ejemplo, Skinner (1953).

THÉMATA. Revista de Filosofía, No 51 enero-junio (2015) pp.: 71-86

doi: 10.12795/themata.2015.i51.04 
dad. Conviene, pues, que nos preguntemos por lo que sucede realmente en cada uno de los tres episodios.

Respecto al primero, siempre me ha asombrado que su carácter metafórico no resulte universalmente obvio. El centro que se disputan el Sol y la Tierra es un centro geométrico (si no de un "perfecto círculo", al menos de una forma con nombre reconocido). Pero la supremacía que se concedía tradicionalmente a la Tierra se basaba en que es ella, la Tierra, el hogar de la Humanidad. ¿Por qué esa cualidad -esa superioridad para el desarrollo de la vida- tendría que coincidir con lo que es el punto destacado en el orden geométrico? ¿Por qué el hecho de que la Tierra gire alrededor del Sol va a ser incompatible con la superioridad de la Tierra en el orden biológico? Ciertamente como metáfora ha sido extremadamente útil la inversión copernicana. Y no me refiero sólo a Kant. En el siglo XX, esa metáfora se ha usado a otro nivel, y se acuñó el paralelismo entre el geocentrismo de la antigua astronomía y el egocentrismo de las primeras etapas del niño (Piaget, 1962). Sin embargo, más allá de su valor como vehículo metafórico, la victoria del heliocentrismo sobre el geocentrismo no tiene nada que ver con el puesto del ser humano en el Universo.

Freud es, por supuesto, de los tres, el invitado más dudoso. Por mucho que escribiera de un modo fascinante, poner a Freud en línea con los descubrimientos de la astronomía hacia 1600 o de la evolución biológica en el XIX resulta un poco escandaloso. ${ }^{4}$ Hay que preguntarse qué queda del inconsciente una vez que se tiene en cuenta la herencia primate y el modelado de la personalidad por las sucesivas experiencias y se atiende asimismo a las patologías cerebrales. No es que yo esté descartando taxativamente que pueda haber intuiciones acertadas en la idea de inconsciente de Freud, pero quiero subrayar que hoy es perfectamente lícito y sano poner entre paréntesis el edificio freudiano. Por eso, voy a preferir ver el destronamiento achacado a Freud como incluible en el que subraya nuestra condición animal. Y con ello pasamos a Darwin.

\section{Ser humano y evolución biológica. ¿Hay algo que nos autorice a privilegiar el criterio de la inteligencia?}

Así pues, el cómo se relacione la evolución biológica con el ser humano es, a mi entender, el único punto decisivo en torno a la famosa cita. Abandonando ya, pues, la cita, pasemos al verdadero asunto. ¿Estamos o no autorizados a ver en el ser humano el ápice de la evolución? Mientras permanezcamos dentro del marco de las teorías científicas, no podemos en absoluto invocar el punto de vista teleológico (o teológico) y hemos de abstenernos de pensar en que la evolución pueda tener una meta. Así pues, con el término ápice, estoy

[4] De hecho fue Freud el que se postuló a sí mismo y el que lanzó, pues, la idea de las revoluciones científicas destronadoras que ha llegado a ser tan famosa.

THÉMATA. Revista de Filosofía, №51 enero-junio (2015) pp.: 71-86

doi: 10.12795/themata.2015.i51.04 
queriendo decir simplemente el punto más avanzado. Entendida así la pregunta, ¿cómo podemos contestarla? Por supuesto, para defender la exclusividad de la especie humana, se puede recurrir a que en ella se da la mayor inteligencia y casi el mayor índice de cefalización. Ciertamente esos datos son indiscutibles. Sin embargo, es igual de indiscutible que el guepardo alcanza la mayor velocidad o que la vista del águila es superior a la de los otros animales. Hay, pues, que preguntar: Dejando atrás el chauvinismo humano, inevitable pero que no sirve para mostrar nada, ¿̇hay algo que nos autorice a privilegiar el criterio de la inteligencia? Lo que está claro es que no habrá tal autorización a menos que se pueda mostrar que el avance de la capacidad de conocer coincide con el progreso más general y profundo detectable a lo largo de la evolución biológica, o, en otras palabras, que ese avance no es uno más entre los muchísimos rasgos que muestran progreso en tal o cual parcela de la evolución. ¿Cómo se podría mostrar que ello es realmente así?

Antes que nada, conviene acotar el espacio donde se da realmente el problema. Sabemos que la clase de los invertebrados apareció antes que la de los vertebrados. Asimismo sabemos que aves y mamíferos aparecieron con posterioridad a peces y anfibios. Ciertamente no se está negando con esto que en los últimos 100.000 años haya podido aparecer una nueva especie de escarabajo o de pez. Los invertebrados o los peces siguen siendo tipos productivos de nuevas especies. Sin embargo, el que la clase de los vertebrados, o también la de aquéllos con sangre caliente, sean posteriores a sus respectivos contrarios, es un dato fiable que nos ha sido proporcionado por el estudio de la evolución. Así pues, esto sitúa al ser humano dentro de las clases más recientes. Pero tras esto, o sea, cuando nos situamos en el seno del conjunto de los vertebrados de sangre caliente, es ya mucho más difícil atribuir rótulo alguno de 'última adquisición' a la especie humana. Por supuesto, dentro de los primates la especie humana podría ser la más reciente. Pero eso no nos da lo que estamos buscando. Recordemos, por un lado, que los primates tienen raíces bastante antiguas, y, por otro lado, que especies tan recientes como la humana habrán podido seguramente surgir entre los mamíferos no primates o entre las aves. Así que, cuando vemos al ser humano en el contexto restringido de mamíferos y aves, en ese momento, el criterio que empezábamos a emplear, el de qué es antiguo o reciente filogenéticamente, nos abandona. ¿Hay algún otro criterio que pudiéramos aplicar?

\section{Contra el dualismo: Una digresión necesaria}

Pero antes convendrá explicitar para qué estoy queriendo aplicar criterios. Yo creo que la evolución, lejos de un destronamiento del ser humano, supone justo todo lo contrario. Ciertamente, en la teología rabínica y en la cristiana, se ha sostenido siempre que la alianza entre Dios y los hombres es el por 
qué y el para qué de la creación del mundo, y, por tanto, que el ser humano es la meta y finalidad de la Naturaleza. Pero, como ya he dicho, esta invocación de metas y finalidades está, por definición fuera de lo comprobable: No hay nada que fuerce u obligue a interpretar así los procesos naturales. Así pues, acerca de esta interpretación, sólo cabe hablar de si encaja con los descubrimientos científicos. Y aquí se inserta el asunto de estas páginas. Quizá ese 'encaje' es ahora mejor que antes de que se descubriera la evolución.

Sin embargo, en el curso del último siglo y medio, las cosas se han visto de un modo muy diferente. De hecho, ni siquiera se ha enfocado la cuestión del buen encaje a la que antes nos referimos. Se sigue aún hoy en un paso anterior, el de si hay o no hay compatibilidad entre el hombre como producto de la evolución y el hombre como dotado de libertad moral entendida en sentido fuerte. Los defensores de la evolución la han presentado una y otra vez como una etapa crucial del destronamiento del ser humano. Y, a su vez, la teología ha tendido tradicionalmente a ver en las teorías evolutivas un ataque a la peculiaridad humana y a sus rasgos espirituales. Es verdad que esto empezó a cambiar hace ya al menos 40 años. ${ }^{5}$ Pero lo más habitual y frecuente ha sido, y sigue siendo, considerar que la creación directa de un componente espiritual, una creación sobreañadida al margen de la evolución biológica, defendería mejor la dignidad el ser humano. Resultado: muchos autores religiosos han acabado presentando la Naturaleza como un proyecto frustrado que sería incapaz de alcanzar por su propia dinámica la meta para la que habría sido concebido. El ser humano es presentado en una supuestamente sublime separación de los animales y de la Naturaleza toda, pero ello es a costa de quitarle a la entera creación su grandiosidad. ${ }^{6}$ Aparte de eso, otro resultado, de menor escala ya, pero igual de lamentable, es el de que apenas se ha abordado todavía la gran cuestión de si es posible una libertad moral sin dualismo. Pero en estas páginas sólo nos va a interesar la cuestión relacionada con el primero de los dos resultados.

Es curioso cómo las diferentes herencias intelectuales que gravitan sobre el dualismo y el materialismo han acabado por hacer adoptar al dualismo la postura contraria a la que en buena lógica le correspondería. El dualismo está históricamente ligado a la religión y más en concreto a una religión que acepta a un Dios infinitamente grande y sabio que habría creado todas las cosas. Y, sin embargo, tras los meandros de un siglo y medio de discusión, el

[5] Ejemplo de este cambio, un ejemplo del que nadie dudará que está dentro de la ortodoxia, es Ratzinger, 1973, cuya aceptación plena y total de la evolución biológica le lleva a rechazar incluso la última línea defensiva de la teología anti-evolucionista, a saber, la idea de que el espíritu humano sería un añadido de última hora al resultado de la evolución de la materia. En ese trabajo, la 'creación particular del ser humano' se identifica con el hecho de que lo humano sería la meta perseguida por la entera evolución.

[6] Incluso alguna teología reciente está apostando por introducir, además del alma espiritual, otros sobreañadidos, los diseños para puntos particulares.

THÉMATA. Revista de Filosofía, Nº51 enero-junio (2015) pp.: 71-86

doi: 10.12795/themata.2015.i51.04 
paradójico resultado es que hoy son justo los defensores del dualismo los que niegan la grandeza de la evolución. Según ellos, la trayectoria de los millones de años de evolución habría sido tan ineficaz que precisamente en el momento en que tendría que haber alcanzado su meta teleológica, o sea en el momento de la aparición de los seres humanos, un elemento ajeno a la materia evolucionada tuvo que serle añadido. En definitiva, la chapuza que los dualistas introducen en la creación es incomparablemente peor que todos los supuestos defectos que el materialismo actual pone de relieve en la evolución. Esos supuestos defectos-causados por el bricolage, la exaptation, el kluge, en definitiva por el 'aviarse con lo que estuviera disponible'-no son sino las características intrínsecamente necesarias de la evolución. En cambio, la ineficacia definitiva que supone no ser capaz de llegar al final del camino, ese defecto máximo y crucial, no le es atribuido a la evolución por los materialistas sino por los dualistas. Por decirlo en toda su crudeza: es la evolución que contemplan los materialistas, y no la de los dualistas, la que sería digna de ser la creación de Dios.

Como dije, algunos teólogos empezaron hace ya años a dejar atrás ese punto de vista. Sin embargo, toda esta teología y filosofía a la defensiva, todo este debate que busca minimizar los supuestos peligros de la evolución, no se ha acallado todavía. Pero lo que aquí nos interesa realmente no es combatir esa postura, sino abordar la cuestión, más positiva y menos frecuentada, de si aquel 'encaje' es ahora mejor que antes de que se descubriera la evolución.

\section{Mirando a la evolución en su conjunto. La tendencia a la cap- tación de la realidad}

Para ello, debemos volver a la cuestión que quedó pendiente arriba. ¿Hay algo que pueda realmente autorizarnos a presentar como ápice o cúspide de la evolución, no ya a mamíferos y aves, sino justo a los seres humanos? Empecemos por ampliar el cuadro e incluir a los vegetales y sus tropismos.

¿En qué sentido son semejantes el deseo de un mamífero y el tropismo de un vegetal, y en qué sentido son diferentes? En los dos casos el organismo es dirigido hacia aquello de lo que tiene necesidad: las hojas del vegetal, hacia la luz, y el lobo, hacia el conejo. Pero, mientras que las hojas o las raíces crecen, el lobo corre. ¿Es, entonces, la presencia / ausencia de movimiento lo que separa el tropismo y el deseo? Creo que para decantarnos por la respuesta negativa bastará pensar en los organismos unicelulares. Es difícil que nadie quiera atribuirles un deseo propiamente dicho, y sin embargo, ellos se mueven, con movimiento y no sólo crecimiento, hacia lo que necesitan. O podemos mirar también a los animales sin un cerebro propiamente dicho, a los insectos, por ejemplo, a los que les basta con sus ganglios sensoriales y ganglios motores. Recordemos cómo descubre la abeja las flores. Su ojo compuesto transmite a los ganglios sensoriales la información, primero, de que hay color de flores, y 
segundo, de en qué dirección hay más. A continuación de eso, los ganglios sensoriales ponen en acción el adecuado ganglio motor. Esta sensibilidad al color puede ser sustituida en otros invertebrados por la sensibilidad a un compuesto químico, o al calor, o a la cercanía al polo magnético. Pero en todos los casos el invertebrado no tiene en absoluto que computar la distancia a la que se halla el estímulo. Lo único decisivo es la cantidad de estímulo, o, para concretar, la cantidad de color que impacte sobre cada zona del ojo compuesto. La zona en la que haya más color es la que activará su correspondiente ganglio motor. Pero, podría objetar alguien, ¿acaso no le importa al organismo si ha de volar más o menos para llegar a las flores? La clave estriba en que para la economía del organismo vale lo mismo-es totalmente indiferente-el que haya muchas flores lejanas o pocas cercanas. Más esfuerzo con más rendimiento, por un lado; menos esfuerzo con menos rendimiento, por el otro: ¿vale la pena distinguirlos? En definitiva, hay un cierto sentido en que los mecanismos de los animales sin un verdadero cerebro se parecen a los tropismos vegetales más que a las percepciones y los deseos.

La verdadera percepción, la de los animales superiores, es distal, o sea, percibe objetos y los ubica en el espacio más allá del organismo. Enfoquemos los dos puntos subrayados. Objetos, no meros estímulos como eran el color, el calor o los compuestos químicos: esto es el primer punto. El segundo es que los contenidos perceptivos, aun dándose dentro del organismo, son situados por el organismo como fuera de él. Ambos puntos realmente coinciden, por más que los hayamos separado en la descripción. Ningún estímulo sensorial se convierte en objeto si el organismo no lo sitúa a una determinada distancia respecto del centro que es el organismo mismo. (El espacio egocéntrico es casi con seguridad el que es captado en la percepción originaria, tanto del niño como de la evolución.) E igualmente, ¿para qué un organismo iba a conseguir la hazaña de captar esa distancia, o sea, de captar algo que por definición está más allá de sus receptores sensoriales, si no es para situar a esa distancia a los objetos? ${ }^{7}$ Volvamos al contraste con la abeja. Mientras que para ésta muchas flores lejanas contaban lo mismo que pocas flores cercanas, para un animal con verdadero cerebro, en cambio, un depredador (o una presa) sigue siendo un depredador (o una presa) ya esté a 40 metros o a 3 metros. La cantidad de estimulación que impacta sobre sus órganos sensoriales variará, claro, dependiendo de la cercanía o lejanía del objeto, pero el objeto seguirá siempre siendo percibido como el mismo objeto.

Intentemos explicitar en qué dirección ha supuesto un avance la aparición evolutiva de la percepción. Vegetales o insectos no captan en absoluto la realidad externa a ellos. (Entiéndase aquí por realidad externa lo que en la

[7] Lo que proporcionan los receptores sensoriales, como la retina, por ejemplo, es sólo el 'estímulo próximo', como lo llamaba la semántica causal de Dretske (1983). A partir de ahí, el cerebro ha de construir 'el estímulo distal o causal'.

THÉMATA. Revista de Filosofía, Nº51 enero-junio (2015) pp.: 71-86

doi: 10.12795/themata.2015.i51.04 
terminología de Dennett se llama 'lo distinto al self'. Ciertamente la diferenciación entre el self y el no self es constitutiva de cualquier organismo vivo. Sin embargo, el que esa diferenciación se haga consciente para el organismo es un paso nuevo y mucho más complejo. $\left.{ }^{8}\right) \mathrm{Y}$ de ahí también que vegetales e insectos no necesiten grado alguno de conciencia, sino que sean en ese aspecto lo mismo que un termostato. Veamos esto último poco a poco. ¿Cuándo necesita un organismo sentir, o, en otras palabras, tener algún grado de conciencia? Yo diría que eso llega a ser indispensable sólo cuando, con la verdadera percepción, el organismo ha de dar un centro a las distancias en las que sitúa a los objetos, o, dicho de otra manera, cuando ha de sentirse él mismo el centro respecto al cual computar las distancias. Ésa sería la más originaria e indispensable función de la conciencia. Después podrán llegar nuevas funciones, de modo que la conciencia se haga de placer o de hambre, y (después quizá: Key, 2014) de dolor, y (aún más adelante) de cansancio o miedo. Pero todas esas nuevas funciones no serían indispensables en un principio. Recordemos que la búsqueda de los elementos necesarios para la supervivencia se lleva perfectamente a cabo en vegetales, organismos unicelulares o insectos, sin que para explicar tal búsqueda haya que recurrir a deseos o satisfacciones conscientes. Por eso, si se acepta que las modificaciones fuertes llegan a establecerse sólo cuando desempeñan alguna función útil para la que son necesarias en el sentido más estricto, si se acepta eso, entonces la forma primera, la más originaria, de la conciencia habría sido la de centro de la distancia.

Pero enfoquemos también el otro punto, la captación de la realidad externa. Gracias a esa captación, el deseo de un mamífero (o, más en general, de cualquier organismo capaz de percepciones propiamente dichas) le impulsa a buscar en el espacio exterior algún objeto parecido a los que, o bien provocaron en el pasado la satisfacción de ese deseo, o bien precedieron más o menos inmediatamente a esa satisfacción. Esa búsqueda ha de ser lo más inteligente que sea posible. Frente al automatismo del insecto, el mamífero necesita aprender, ser flexible y ponderar los distintos factores que puedan ser relevantes. Cuando se han dejado atrás los recursos afines al tropismo, es decir, cuando se ha alcanzado el nivel de búsqueda de objetos, resulta útil que la captación de la realidad sea lo más amplia posible. Y eso es lo que intentan los animales con cerebro.

Tras los detalles de los últimos párrafos, quizá convenga repetir lo que se dijo al principio. Volvamos, pues, a delinear cuál está siendo nuestra argumentación. El que la especie humana es la más inteligente es un hecho obvio, y argumentar a favor de ese hecho no tendría sentido alguno. Lo que estamos

[8] Huelga decir que el organismo no captará nunca la realidad externa en sí misma. Para mostrarlo no tenemos siquiera que invocar el famoso asunto de los límites del conocimiento humano. Aquí nos basta con recurrir a Uexküll y a los mundos diferentes que para distintas especies puede suponer un mismo y único lugar.

THÉMATA. Revista de Filosofía, No51 enero-junio (2015) pp.: 71-86

doi: 10.12795/themata.2015.i51.04 
intentando mostrar es algo mucho más controvertido, a saber, que el avance en la captación de realidad es el tema de fondo de todo el progreso de la evolución biológica. Hasta ahora hemos señalado, primero, que en vegetales e insectos el conjunto de medios que cada organismo emplea para su supervivencia no incluiría en absoluto la captación de objetos, y, segundo, que en aves y mamíferos sucede lo contrario. ${ }^{9}$ Pero con esto no hemos rebasado lo que el mero criterio de la menor antigüedad evolutiva de los vertebrados de sangre caliente ya nos había ofrecido. Por eso, conviene que enfoquemos ahora los primates no humanos. ¿Se da realmente en ellos el arriba sugerido tercer avance en el conocimiento de la realidad? Y si fuese verdad que se da, ¿tiene ese avance alguna semejanza, alguna dirección compartida, con la exclusividad humana más básica y primitiva que podamos encontrar?

\section{Comparando los avances en el conocimiento de la realidad que hemos llamado segundo y cuarto}

Para acercarnos al asunto del tercer avance, intentemos antes contraponer el segundo y el cuarto. En casi todas las especies animales, los objetos son captados sólo en su relación al organismo que los percibe. Lo que interesa de la realidad percibida es si conviene hacerse con ella, o, por el contrario, evitarla, y, en el caso de que se trate de una realidad capaz de autopropulsión, si huye o ataca, y, en el caso de que se trate de un congénere, si es subordinado o superior. En definitiva, lo que importa de cada realidad percibida es siempre y exclusivamente su relación con el que percibe. Eso es lo único que captan los animales dotados de percepción y conciencia. Así pues, esa captación ignoraría la interioridad, el punto de vista interno, que algunos objetos-sus congéneres, por lo pronto-poseen. Las aves y la mayoría de los mamíferos, aunque es casi seguro que tienen esa interioridad o punto de vista interno, serían incapaces de captar estados conscientes ajenos. Es lógico que esa adquisición evolutiva relativamente tardía que es la conciencia animal ocupe asimismo un puesto sumamente tardío entre los objetos que llegan a ser conocidos.

En cambio, los seres humanos somos unos verdaderos virtuosos en tales operaciones. ${ }^{10}$ Constantemente estamos atribuyendo estados conscientes a los

[9] ¿Reptiles y anfibios? La rana, y el punto negro de la mosca que pasa ante ella, ha sido un caso muy enfocado (véase, por ejemplo, Lloyd, 1989). Y, respecto a los reptiles, sabemos que al final de la Era Secundaria hubo especies de transición hacia las novedades del Terciario. Pero en esta exposición, he optado por admitir conciencia sólo allí donde parece más seguro, o sea, en aves y mamíferos.

[10] Por supuesto, la captación de los estados mentales ajenos servirá en la mayoría de las ocasiones sólo para hacer más eficaz el mismo tipo de conducta que se da en las demás especies animales. (El error que supone querer saltar directamente desde la empatía al sentido moral genuino es un error que ya ha sido denunciado tantas veces que no merece la pena insistir en ello.) Sin embargo, eso no menoscaba en absoluto la novedad que supone esa ampliación del conocimiento de la realidad externa.

THÉMATA. Revista de Filosofía, Nº51 enero-junio (2015) pp.: 71-86

doi: 10.12795/themata.2015.i51.04 
que nos rodean. Desde los 80 viene creciendo una corriente de investigación, la llamada 'teoría de la mente', que estudia la captación que el sujeto tiene de la mente ajena y propia. (Puesto que las divisiones internas de esa corriente o los cambios de énfasis a lo largo de su trayectoria no son asuntos prioritarios aquí, los paso por alto.) En resumen, al ser capaces los seres humanos de llegar a la subjetividad ajena, la captación que ellos hacen de la realidad tiene un espesor inédito hasta entonces en la evolución. No se trata sólo de una novedad cuantitativa, sino cualitativa. Además, por si alguien objeta que ése no es más que un aspecto y no de los más esplendorosos de la exclusividad humana, conviene añadir que hay un acuerdo cada vez más amplio en que la captación de la subjetividad ajena podría ser la exclusividad humana más básica, a partir de la cual podrían derivarse históricamente los demás rasgos (a empezar por el lenguaje sintáctico: ver Bejarano, 2011, sección 4, o Bejarano 2014) que hoy caracterizan a los humanos.

Pero esta contraposición entre mamíferos en general y humanos podríamos hacerla más útil en favor de aquel 'buen encaje' del que venimos hablando, bastante más útil realmente, si atendemos a una posibilidad que cuenta ya con cierto fundamento. La ampliación cualitativa que constituye la exclusividad humana tendría antecedentes muy concretos en los primates no humanos. Esos antecedentes se quedan, sí, muy lejos de lo que es exclusivamente humano, y así nos permiten subrayar esa exclusividad. Pero a la vez-y esto es lo que ahora me interesa subrayar-, son verdaderos antecedentes. Estos antecedentes, o sea, lo que antes llamamos el tercer avance, estaría constituido por la capacidad de los primates en general para detectar estados internos de sus congéneres. Esta capacidad de los primates, aun siendo el antecedente de la que es exclusivamente humana, tendría una diferencia cualitativa y no meramente cuantitativa con la humana: Eso es lo que, aunque muy resumidamente, nos esforzaremos en defender en el apartado siguiente.

Pero antes glosemos el rumbo seguido en los últimos párrafos. En nuestros días, la scala naturae no puede ya incluir todos los rasgos. Está claro que los tiempos anteriores a Darwin ya no pueden volver. Ahora sabemos que las especializaciones diferentes son incontables y que cada una de ellas tiene su propia trayectoria de avances. Pero, no obstante, quizá se pueda señalar una tendencia que abarcaría toda la evolución. Y así, atendiendo justo a esa tendencia, o sea, a la captación cada vez más adecuada de la realidad, podríamos volver a señalar escalones y cúspide (un término hoy prohibido) en la naturaleza. Por decirlo de otro modo: Es sólo porque no me gusta adoptar gritos de guerra por lo que no adopto el de ‘ Escalones y cúspide en la evolución, sí!' 


\section{Viendo más de cerca el posible avance de los primates}

Pasemos por fin al escalón bien definido en el que yo colocaría a los primates. Aquí, la tarea está mucho menos avanzada que en el terreno de la percepción animal o en de la captación humana de la subjetividad ajena. Es verdad que a principios de los 90 el descubrimiento de las neuronas de espejo de los macacos irrumpió con fuerza, y parecía a punto de sostener la novedad cualitativa ligada a los primates. Sin embargo, han ido surgiendo cada vez más inconvenientes. Primero, la cada vez más borrosa definición de lo que serían las neuronas de espejo o los sistemas de espejo. Después, y como consecuencia de esa indefinición, los problemas acerca de los límites del que estamos llamando tercer escalón. Por un lado, se subraya que cuervos y chimpancés (ésas son las especies concretas usadas en los experimentos) están resultando cada vez más parecidos con respecto a la capacidad de detectar lo que el congénere ve o no ve. Y a partir de ahí los autores neoconductistas (Povinelli sobre todo, pero también Heyes-ver por ejemplo Ray \& Heyes (2011)- y otros muchos) están queriendo borrar toda peculiaridad de los primates. Por el lado opuesto, la capacidad de los chimpancés de detectar lo que el congénere no ha visto (la detección de ignorancia es la que ahora nos importa), esa capacidad que yo, siguiendo a Tomasello, acepto plenamente, parece acercarse cada vez más a aquella captación de falsas creencias ajenas que durante tantos años fue el estandarte de los estudios de la 'teoría de la mente'. ¿Hay pues que renunciar a lo que hemos llamado el tercer escalón? Yo creo que no, y el intento de poner en claro cuál es la frontera entre el tercero y el cuarto ocupa casi la mitad de mis publicaciones durante los últimos 10 años.

El punto de partida sería el hecho de que los primates tienen manos. La novedad evolutiva de la mano radica sobre todo en el hecho de que la mano es la única parte de un cuerpo animal que es bien visible para el sujeto que la posee. De hecho no es sólo que sea vista muy a menudo (ien cada acción de agarrar!) y a la distancia adecuada, sino que además es también perfectamente reconocible por la forma conspicua que le proporcionan los cinco dedos. De aquí que en la mano del primate es donde por primera vez en la evolución se daría la homologación entre una parte del cuerpo del sujeto y su contraparte en un cuerpo ajeno. Este papel de la mano sería anterior y más crucial que el que desempeña en la fabricación de herramientas: No es sólo ni principalmente hacia el homo faber hacia donde tiende la mano del primate. Lo que en un principio se consigue es detectar (o podría ser también adecuado el término 'predecir') cuál es la interioridad postural y proprioceptiva de la mano ajena que se ha observado. La interioridad postural es, desde luego, una parcela muy pequeña y, digamos, grosera de la interioridad o punto de vista interno. Sin embargo, es indudablemente interioridad, y por eso su captación en otro es una novedad radical. 


\section{¿Qué hay de los famosos destronamientos del ser humano?}

Esa homologación de las manos llegaría pronto a sostener la homologación del cuerpo propio (sentido pero no visto) y el ajeno (visto pero no sentido), de modo que al fin los dos cuerpos lleguen a tener las dos vertientes. A partir de ahí surgiría la capacidad de ponerse en los zapatos o el pellejo de otro. ${ }^{11}$ (Ese convencimiento lo adquirí, es de justicia decirlo, no en las noticias de los 90 sobre las neuronas de espejo, sino en la obra de Piaget sobre el desarrollo de la imitación motora en los niños, que data de los 50.) ¿En qué consiste la capacidad de los chimpancés de ponerse en los zapatos de otro? Yo quiero subrayar que ahí el sujeto observador generaría la expectación de qué es lo que él vería o sentiría si él, él mismo, estuviera en la postura, orientación y ubicación en las que se halla el congénere observado. (Esa expectación sería capaz incluso de atribuir al congénere la visión de un objeto que el sujeto no esté viendo en ese momento, con tal de que el sujeto lo haya visto momentos antes. En eso estriba quizá la diferencia entre la habilidad propia de los cuervos, que se reduciría a seguir la dirección de mirada de un congénere y a tener en cuenta las posibles barreras opacas que obstaculizarían esa mirada, y la de los chimpancés, que pasa por colocarse el sujeto en las circunstancias del congénere. $)^{12}$

[11] El nexo directo que yo estoy proponiendo entre mano autovisible e imitación es, pues, diferente al que Arbib lleva proponiendo desde hace más de 10 años. Mientras que Arbib pasa directamente desde el mirroring de la mano a la imitación de gestos simbólicos o del lenguaje, el que yo propongo es el nexo que a través de la homologación de los cuerpos, llegaría a la capacidad de imaginarse el sujeto a sí mismo en la postura, orientación y ubicación en las que se halla el individuo que él está observando .

[12] Dado que el chimpancé puede generar no sólo la expectación de lo que el congénere estará viendo sino también de lo que no estará viendo, resulta el comprobado hecho (pero véase a Povinelli y sus presuntos argumentos para rechazarlo) de que los chimpancés pueden perfectamente atribuir ignorancia al congénere. Respecto a esa atribución, ha habido el intento (por parte, claro está, de autores en el extremo opuesto de Povinelli) de acercarla a la captación de falsas creencias, a pesar de que hasta ahora en los experimentos esa captación aparece como exclusivamente humana. Pero, a mi juicio, la atribución de ignorancia es muchísimo menos demandante. La atribución de ignorancia (respecto a un cambio de sitio del alimento, por ejemplo) puede ser sostenida, o bien mediante el mero gaze-following de los cuervos, o bien, cuando la tarea se hace más complicada, mediante las expectaciones peculiares propias del primate. Pero intentemos ahora llegar desde esa atribución de ignorancia a la captación de la falsa creencia ajena. $\mathrm{O}$, más concretamente, ¿qué pasa en el chimpancé sujeto cuando el congénere mira de nuevo al sitio donde antes (antes del desplazamiento que él, el congénere, no vio) estaba el alimento? ¿Podrá entonces el sujeto atribuirle al congénere la conservación de la previa, ahora falsa, creencia del congénere? Yo respondo que con el mero recurso de la expectación no podrá el sujeto hacer esa atribución. El chimpancé sujeto se volverá a poner en la ubicación, postura y orientación del congénere, y detectará qué es lo que él, el sujeto mismo, vería si estuviera en esas circunstancias, y finalmente atribuirá al congénere ese campo visual. Pero si esto se basa sólo en expectaciones, entonces serán las expectaciones del sujeto las que intervienen. Y estas expectaciones son las de quien ya sabe dónde está ahora el alimento. Así pues, la captación de la falsa creencia ajena no puede ser sostenida por la mera expectación. Los hechos que teníamos como punto de partida, o sea, los éxitos y fracasos de los chimpancés en los distintos diseños experimentales, no nos engañaban. En ese sentido, la frontera superior del tercer escalón se mantiene sin deterioro alguno.

THÉMATA. Revista de Filosofía, Nº51 enero-junio (2015) pp.: 71-86

doi: 10.12795/themata.2015.151.04 
Pero al lado de esos avances que habrían conseguido los primates, tenemos que poner de relieve los límites de su capacidad para colocarse en el pellejo de otro. Estos límites, propongo, se manifiestan en cuanto el sujeto ha de captar en el individuo observado un estado mental que sostenga la interacción de ese individuo con el sujeto. Nótese que un estado mental de estar interactuando o comunicando con el sujeto no puede ser nunca, en modo alguno, una expectación propia del sujeto. Las expectaciones (o sea, los perfiles vacíos que predefinen lo que habrá de llegar para llenarlos) apuntan siempre a estados que serían posibles en el sujeto, pero el estado de interactuar o comunicar distalmente con el sujeto es imposible para el sujeto. ${ }^{13}$ Aquí surgiría la peculiaridad básica humana. El chimpancé sólo puede compaginar sus contenidos propios y las expectaciones captadas en otro; el ser humano, en cambio, puede ser simultáneamente consciente de dos verdaderos contenidos diferentes: uno suyo propio y otro que le es intrínsecamente ajeno. Ésa sería la diferencia entre el tercer y el cuarto escalón que respecto al conocimiento de la realidad ha producido la evolución. ${ }^{14}$

\section{7. ¿Permitido hablar de nuevo del puesto culminante del ser humano?}

Pero volvamos ya a lo que dijimos al inicio. Es imposible, desde luego, probar, apoyar o refutar la afirmación de que el ser humano constituiría la meta de la evolución. Pero sí cabe decir que el que se pudiera asignar el puesto culminante de la evolución al ser humano encajaría bien con esa idea.

Aquí hemos propuesto que realmente se les puede asignar ese puesto a los humanos, y que eso se logra de un modo más concreto y profundo cuando se enfoca la evolución y se descarta la scala naturae entendida al modo antiguo y obsoleto. La tendencia más general entre las muchísimas y variopintas tendencias de avance que se evidencian en la evolución habría sido el avance en el conocimiento de la realidad externa al organismo. Si eso es así, entonces ese criterio asigna obviamente al ser humano el puesto culminante.

Como el lector se habrá dado cuenta hace tiempo, estas páginas, a diferencia de otras publicaciones mías, no han buscado primariamente apoyar o desplegar hipótesis. He mencionado, sí, qué es lo que caracteriza a la percepción de los animales con verdadero cerebro, y sobre todo cómo se distinguirían los avances que he llamado tercero y cuarto. Pero lo que aquí he

[13] Por explicitar lo que el adverbio 'distalmente' ya indica: No me estoy olvidando, no, del habla interior. Le aseguro al lector que el habla interior es precisamente uno de mis asuntos predilectos.

[14] En Bejarano, 2011 y 2015, he defendido que a) la recepción del gesto de apuntar como un gesto comunicativo, b) las emociones autoconscientes del tipo de la vergüenza o de la que Darwin describe como causa del rubor, y c) los planes para tareas a cuatro manos, requieren justo esa peculiaridad humana que acabo de describir.

THÉMATA. Revista de Filosofía, N51 enero-junio (2015) pp.: 71-86

doi: 10.12795/themata.2015.i51.04 
pretendido ante todo es explicar por qué y para qué me ha interesado defender tales hipótesis.

Por último, la gran cuestión: ¿qué seguridad ofrecen los elementos propuestos? Lo que está claro es que, entre todos ellos, el que, con diferencia, está por ahora menos asentado en la bibliografía es el avance peculiar de los primates no humanos: ¿son aceptables las fronteras superior e inferior que yo me he esforzado en asignarle? Así pues, hay que subrayar que todo esto se ofrece como una propuesta, sí, pero también y sobre todo como una invitación a trabajar. 


\section{Referencias bibliográficas:}

Arbib, M.A. (2005). From Monkey-like Action Recognition to Human Language. Behavioral and Brain Sciences, 28, 105-167.

Bejarano, T. (2011). Becoming human: From pointing to syntax. Benjamins.

Bejarano, T. (2014). From holophrase to syntax. Humana.Mente, 27. http://www.humanamente.eu/

Bejarano, T. (submitted). In Your Shoes When You Look at Me: Clearcut human uniqueness

Bugnyar, T. \& Heinrich, B. (2005). Ravens differentiate between knowledgeable and ignorant competitors. Proceedings of the Royal Society B, 272, 1641-1646.

Dennett, D. (1991). Consciousness Explained. Boston: Little, Brown \& Company

Dretske, F. (1983). Precis of 'Knowledge and the Flow of Information', Behavioral and Brain Sciences, 6, 55-63.

Key, B. (in press). Fish do not feel pain and its implications for understanding phenomenal consciousness. Biology and Philosophy.

Lloyd, D. (1989). Simple minds. MIT

Piaget, J. (1945). La formation du symbole chez l'enfant. Delachaux \& Niestlé.

Piaget, J. (orig. 1962). Comentarios sobre Vygotsky. En Vygotsky, L. Pensamiento y Lenguaje. La Pléyade.

Povinelli, D. J. \& Vonk, J. (2004). We don't need a microscope to explore the chimpanzee's mind. Mind and Language, 19, 1-28.

Ratzinger, J. (2011, orig. 1973). Creación, Gracia, Mundo. La fe en la creación y la teoría de la evolución. En Fe y Ciencia: un diálogo necesario (pp. 117-130). Sal Terrae.

Ray, E. \& Heyes, C. (2011). Imitation in infancy. Developmental Science, 14, 92-105.

Skinner, B. F. (1953). Science and human behavior. New York: The Macmillan Company.

Tomasello, M., Call, J. \& Hare, B. (2003). Chimpanzees understand psychological states-the question is which ones and to what extent. Trends in Cognitive Sciences, 7, 153-156. 